\title{
PRESENTACIÓN
}

\section{Sujetos que piensan más allá del Estado y el capital}

\author{
Rafael Sandoval Álvarez
}

$M$ ás allá del Estado y el capital es un enunciado que alude a sujetos que no sólo están en contra del capital y se niegan a pensar y a actuar en los márgenes del tiempo y los espacios que el Estado determina, sino que ensayan ir más allá en sus formas de hacer política, crean su propio horizonte histórico sin perder la conciencia de las contradicciones y las ambigüedades de las relaciones sociales de la dominación capitalista que habitamos. Más allá del Estado y el capital tiene que ver con los sujetos que niegan la negación de que son objeto por el tipo de relaciones sociales que impone el capital y la burocracia que opera sus intereses desde el Estado, sujetos que en el despliegue de su subjetividad emergente generan resistencia anticapitalista y crean desde ahí proyectos de autonomía. Más allá del Estado y el capital es ir en contra de la dominación y erigirse como sujetos con conciencia histórica y política, sujetos en perspectiva de autoemancipación como proyecto de futuro. Es una situación que implica asumirse como sujetos que imaginan radicalmente otro mundo de relaciones sociales, sustentado en un imaginario social instituyente donde el que mande, mande obedeciendo. Se trata de pensar desde la perspectiva del sujeto, de dar cuenta del horizonte histórico que reivindica la autonomía y la emancipación de manera que se exprese cómo - consciente o inconscientemente- se hace política desde un estar-siendo en la cotidianidad. Reconocer que la realidad y el conocimiento son resultado del hacer social y la reflexividad en un contexto de luchas y resistencia a la dominación, la explotación, la opresión, la represión y el despojo.

Una gran cantidad de movimientos sociales se ha manifestado de forma evidente en los últimos 20 años: de diferentes clases y sectores sociales, de organizaciones sociales y colectivos - pueblos, comunidades, familias, grupos barriales, comunidades campesinas, etc. - que reivindican su capacidad y necesidad de reflexionar de manera autónoma y producir sus propios documentos de análisis y estudio. Todo esto resulta de la reivindicación que hacen de su derecho a autogobernarse, a autogestionar su producción alimentaria, su salud y su educación.

Los procesos de rebelión indígena, de comunidades barriales y de trabajadores de las maquilas, desempleados, mujeres y jóvenes en América Latina han mostrado la emergencia de una subjetividad que suscita un cambio en los modos de hacer política porque cuestionan la centralidad del Estado y han

\section{Subjects Thinking Beyond State and Capital}

Rafael Sandoval Álvarez: Instituto Nacional de Antropología e Historia, Centro Regional Jalisco Guadalajara, Jalisco, México rafaelsandoval57@yahoo.com

Desacatos, núm. 37, septiembre-diciembre 2011, pp. 7-16 
iniciado proyectos de autonomía en ámbitos de producción, educación, salud, cultura, etc. No pocos sujetos se reconocen como tales y se posicionan frente a la posibilidad de una manera de pensar la política y el futuro que anuncia un por-venir sin Estado capitalista, sin sistemas de partidos - que son modos de relación social de dominio-, en que las formas de representación y delegación nada tienen que ver con la idea de la democracia como poder del pueblo, para el pueblo y por el pueblo. Estos sujetos configuran miles de colectivos y organizaciones que forjan una ruptura con el discurso hegemónico que tiene al poder y la dominación como objeto de la política. Ello debe ser estudiado y reconocido, pues estamos frente a una praxis innovadora que pretende construir un futuro diferente a las relaciones del mandar y obedecer en la forma de gobierno. En este número de Desacatos se analiza dicha pretensión.

Pensar desde la perspectiva del sujeto va más allá de rebelarse ante los gobiernos autoritarios, de exigir ser partícipe de las decisiones en la distribución en el diseño de las políticas públicas. Se trata de ir más allá de los espacios y los tiempos de organización, decisión y definición de programas y proyectos del Estado, incluidas las organizaciones no gubernamentales que han servido como mediación del Estado y las organizaciones capitalistas transnacionales de todo tipo, pasando por las instituciones de financiamiento de proyectos privados de asistencia social y de Iglesias que han operado igual para la cooptación o la gestión ante el Estado.

El desafío es dar cuenta de experiencias que muestren el proceso que abarca miles de iniciativas político-organizativas en todos los continentes que tienen como horizonte histórico la autonomía y la organización al margen de los espacios y los momentos que marcan el Estado y sus instituciones. Posicionar la idea y las formas de hacer que hemos enunciado como ir más allá del Estado y el capital implica mostrar que los sujetos anticapitalistas -consciente o inconscientemente- han instituido relaciones que les permiten sobrevivir y resistir a la dominación política, a la explotación de su trabajo, al despojo de sus territorios, a la opresión y represión de que son objeto cuando luchan y protestan ante todo ello.

Para hacer política más allá de los márgenes que impone el Estado y no permanecer en los límites del mercado capitalista estamos obligados a observar las innovaciones en la autogestión de la producción, la educación y la salud. Si miramos las formas de hacer política - antes soterradas- que emergen a la superficie de lo social, podremos poner en práctica nuevos proyectos de autonomía o sobrellevar de mejor manera los que ya existen. En consecuencia, el discurso y la práctica anticapitalistas de ir más allá del Estado y el capital se sostienen en el reconocimiento de los proyectos de autonomía que miles de colectivos y organizaciones sociales han emprendido durante las últimas décadas - potenciados de manera extraordinaria a partir de la experiencia zapatista, de los municipios autónomos y las juntas de buen gobierno que se han sostenido durante más de diez años por la propia capacidad desplegada y otra forma de construir lo colectivo- sustentados en la conciencia política e histórica de los pueblos que saben que es posible deshacerse del dominio capitalista.

Posicionar las formas de hacer inspiradas más allá del Estado y el capital implica considerar que las posibilidades de vivir dignamente dentro de los márgenes del mercado capitalista y de la farsa de la legalidad democrática que impone el sistema político están cerradas, así como tener en cuenta que el discurso y las formas de hacer política liberales han entrado en una crisis profunda, tanto en su versión de izquierda como de derecha. Supone haber pasado por la experiencia de lucha y resistencia contra la dominación desde el territorio de los sujetos -independientemente del tamaño de la contienda, pues la resistencia anticapitalista es la plataforma para desplegar proyectos de autonomía-, porque desde ese espacio se alimentan las relaciones sociales de solidaridad y apoyo mutuo, propias y necesarias en la vida cotidiana de las comunidades, barrios y pueblos. 


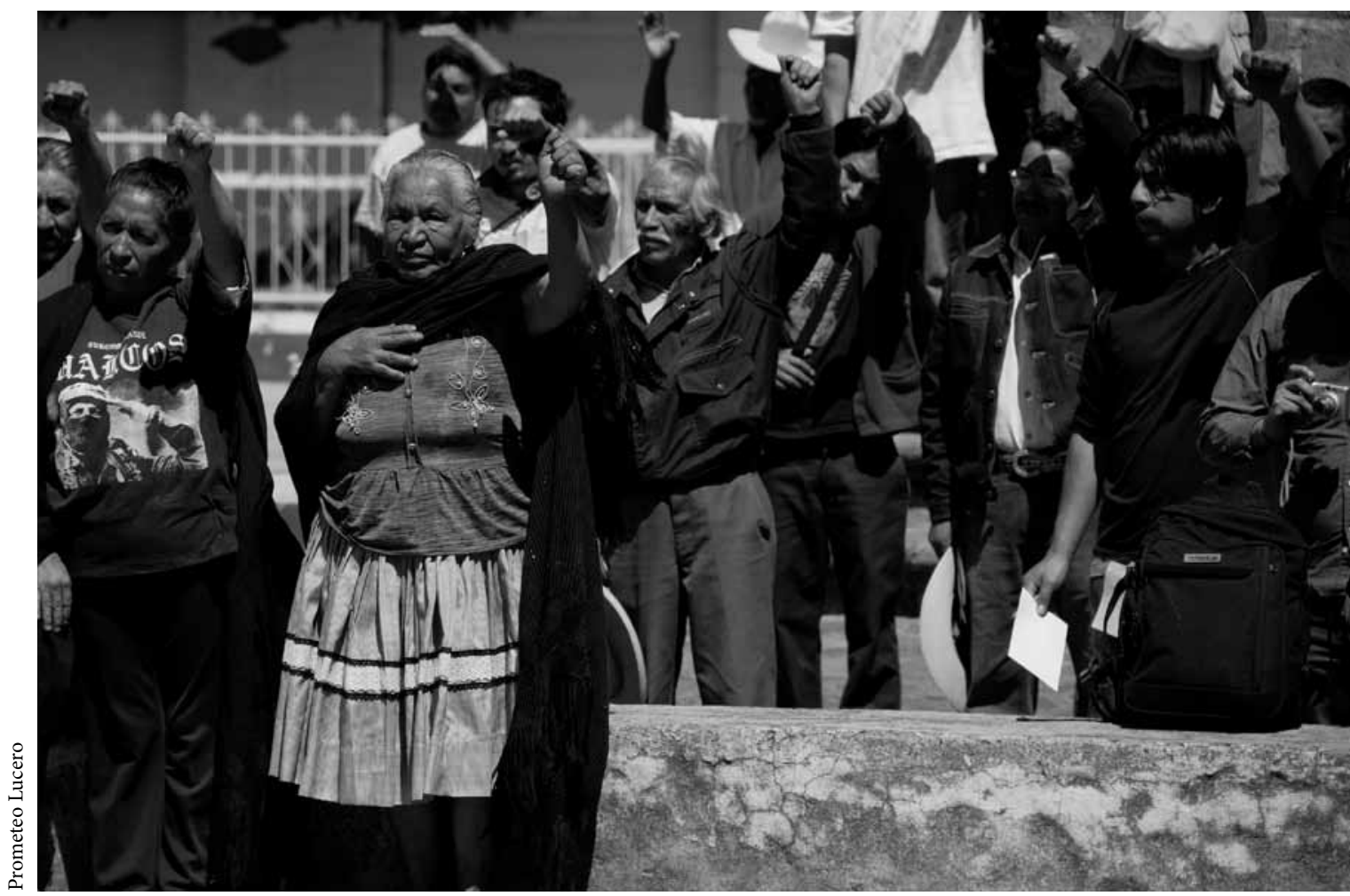

Aspectos del Congreso Nacional Indígena en Nurio, meseta purépecha de Michoacán, 6 y 7 de marzo de 2011.

Desplegar la posición política, ética y epistémica de formas de hacer que van más allá del Estado y el capital significa dejar de hacer política pragmática e instrumental, decir no a la realpolitik, que es negar el realismo político con sus connotaciones liberales y positivistas. Incluye también liberarse de los juegos discursivos propios de la estrategia de la geopolítica y la acumulación de fuerzas, pues de suyo esta lógica corresponde a los déspotas ilustrados que habitan el supuesto de que hay quien sabe y quien no sabe, consideran obligatorio pensar en clave de correlación de fuerzas y de formación de dirigentes, es decir, de relaciones de dominio. Esta última es una cuestión paradójica, puesto que la clase capitalista y sus estrategas del poder militar saben que no es posible ninguna guerra que ponga en juego la correlación de fuerzas con armas de destrucción total. Por ese motivo durante más de una década han preparado a los ejércitos nacionales para ejercer funciones de policía y control de población, y ya no más para la defensa del territorio nacional. Dicho de otro modo, los ejércitos al servicio del imperio del capital —en la forma de guerra total contra la humanidad - implementan la contrainsurgencia como estrategia de guerra de baja intensidad permanente en cada país, promueven la sociedad del espectáculo, donde el autoritarismo y la forma legal implantan la explotación y la opresión como cualidad del sistema social.

Sería difícil dar cuenta de todas las experiencias que han dado el salto para pensar más allá de la racionalidad capitalista y tener por centro de atención la lucha por el control del Estado. Sin embargo, podemos destacar algunas experiencias que han trascendido en forma de textos y debates registrados. Entre los últimos relevantes, James C. Scott (2009) en The Art of Not Being Governed. An Anarchist History 
Upland Southeast Asia hace un recuento de cómo cerca de cien millones de personas han logrado "darse a la fuga" durante decenas de años de las fronteras geopolíticas de los Estados-nación en el Sudeste Asiático. En este número de Desacatos se presenta la reseña de este libro realizada por Rocío del Carmen Salcido Serrano.

John Holloway, después de su obra Cambiar el mundo sin tomar el poder. El significado de la revolución hoy (2002), ha escrito Agrietar el capitalismo. El hacer contra el trabajo (2011), donde expone las acciones de sujetos anticapitalistas en el mundo. Dice el autor que han generado grietas tan grandes como la que han abierto los cientos de miles de indígenas zapatistas en México con una experiencia de más de 15 años de hacer autonomía y autogobierno. Todas son muestras de cómo se va agrietando el capitalismo por la lucha y la insumisión de los pueblos. Por su parte, Pierre Clastres (2010) ejemplifica la lucha de pueblos de América del Sur que se mantenían al margen de su racionalidad de poder y dominio al estilo del Estado en $\mathrm{La}$ sociedad contra el Estado. Es imprescindible señalar que el movimiento anticapitalista de la juventud de 1968 - que en Francia involucró a la mayoría de los jóvenes, estudiantes, trabajadores, de los barrios, etc., y en México fundamentalmente a los estudiantes, por mencionar sólo dos casos- ha marcado a tres generaciones. De ellas, los jóvenes, las mujeres y los pueblos indios se han convertido en protagonistas del proyecto de autonomía como sujetos de su historia.

Comienza una nueva fase de lo nuevo que niega la cultura occidental capitalista ${ }^{1}$ y las relaciones sociales de dominación y explotación correspondientes,

\footnotetext{
${ }^{1}$ Cultura occidental con raíces en la greco-romana, cimentada en la ideología del cristianismo, que en su época última — de la formación social capitalista - cumple alrededor de 500 años, si consideramos la mundialización del mercado consumada con la colonización de Mesoamérica y la región inca, o 300 años, si tomamos como relevante el proceso que culminó con la Revolución Industrial de mediados del siglo xviII de la era cristiana. Luego se expresó en la revolución político-liberal de 1789 en Francia.
}

que de manera contradictoria y ambivalente tiene indicadores que apuntan al principio de su fin -al menos como la conocemos hasta ahora-, siempre y cuando siga habiendo rebeliones y proyectos de autonomía de los pueblos del mundo. Los momentos históricos del debate político y teórico de los últimos 150 años, instituyentes del discontinuo devenir de ese hacer contra y más allá de la dominación capitalista, asientan el proceso histórico de sujetos sociales que reivindican proyectos de futuro que significan rupturas con el canon de la teoría revolucionaria y que intentan ir no sólo en contra, sino más allá de las formas de hacer política del paradigma de la realpolitik y del supuesto de que el fin de la acción revolucionaria pasa por la toma del poder político y el control del Estado.

Esa historia teórico-política ha sido dinamizada por el debate y la práctica política del movimiento zapatista del Ejército Zapatista de Liberación Nacional (1994 y 1996), que ha privilegiado las formas de hacer política des-investidas de la idea de poder entendido como el control del Estado capitalista y ha cuestionado ese aspecto de otros movimientos y sujetos sociales que han trazado sus desafíos y horizontes de futuro en un contexto donde la izquierda partidaria ha asumido el poder gubernamental en varios países de América Latina. ${ }^{2}$

Entre los sujetos que han generado pensamiento anticapitalista y que han trascendido por su producción editorial podemos señalar a Theodor Adorno (1992), Walter Benjamin (2008) y Ernst Bloch (2004) en la primera mitad del siglo xx. Estuvieron presentes en la primera etapa del colectivo del Institut Für Sozialforsschung, independiente de la Universidad de Frankfurt que, en su carácter de institución privada, no observó la aplicación de las leyes antisemitas de la República de Weimar y que, como señala Stefan Gandler (2009), permitió a los miembros de la que hoy conocemos como Escuela de Frankfurt impartir

\footnotetext{
${ }^{2}$ Los países de Latinoamérica donde los partidos que se autodenominan de izquierda ganaron elecciones y asumieron el control del aparato del Estado son Brasil, Chile, Argentina, Uruguay, Ecuador, Bolivia, Nicaragua, El Salvador y Venezuela.
} 
clases e investigar lo que era imposible en otras instituciones científicas de Alemania antes del nacionalsocialismo. Habría que tener en cuenta al colectivo Socialismo o Barbarie en Francia, que cuenta a Cornelius Castoriadis como el más conocido de sus integrantes. Socialismo o Barbarie sugiere presupuestos epistémicos y éticos que aluden a la reivindicación del reconocimiento del sujeto como centralidad en la construcción del saber.

Esos colectivos y sujetos han hecho aportes sobre asuntos fundamentales, como el reconocimiento de la subjetividad en la historia y la perspectiva del pensar histórico en oposición a la historia oficial hegemónica (Benjamin, [1955] 2001). También han destacado la capacidad del sujeto de negar la negación de que es objeto por el capital y el Estado (Adorno, 1992); han llamado la atención acerca de la dominación y la resistencia como premisa para entender la explotación y la fetichización del trabajo y el capital, así como sobre la facultad de pensar el futuro desde la acción y la imaginación de lo que es un embrión en el presente (Bloch, 2004); han profundizado en el imaginario social instituyente que nace del imaginario radical de los sujetos como colectivo anónimo y en la singularidad del individuo social (Castoriadis, 2003).

Esta perspectiva viene de más atrás, pero la marginación en la producción editorial limitó la circulación de las ideas, a lo que se sumó la censura tanto de la izquierda como de la derecha liberal. Podemos rastrear algunos indicios en los debates de la segunda mitad del siglo xIx entre Bakunin y Marx, y entre éste y Proudhon. La polémica se centraba en la organización, la autonomía y el autogobierno de los sujetos sociales y el cuestionamiento a la necesidad de vanguardias partidarias y la toma de control del Estado, dos horizontes políticos desde los que se pensaba la transformación social hacia el futuro. En 1905-1917 encontramos, en el contexto de la Revolución Rusa, el debate Lenin-Kropotkin (2001) y Lenin-Nestor Makhno (s/f a), y después de 1917 las críticas a los bolcheviques hechas por anarquistas como Volin (2007), Archinov (2008) y Avrich (s/f), quienes eran parte del grupo Dielo Truda, una organización de rusos exiliados que participaron en la experiencia anarquista de Ucrania. Este debate planteó la idea de que la revolución no podía ser un acto inaugural, espontáneo, pues de ese modo no había garantía de su duración, y consideraba que una sublevación de pocos días no podía hacer más que derribar un gobierno para poner a otro. Algunas de esas reflexiones están contenidas en lo que Bakunin denominó "revolución auténtica":

la revolución "se hace", es decir, se vive, y sólo en la medida en que transforman las condiciones reales de existencia... Condiciones de una vida digna, para lo cual el problema es, cómo "abolir completamente, en el principio y en los hechos, todo eso que se llama poder político... para convertir la utilización del otro como medio de sus fines, el deseo de la gloria o el reconocimiento" (Bakunin, citado por Velasco, 1993: 178,191 y 203).

Para dar seguimiento a ese tipo de pensamiento habría que llegar a la mitad del siglo xx y adentrarse en los movimientos anticoloniales: la rebelión de Argelia —en la que tuvieron participación militante Frantz Fanon ${ }^{3}$ y Albert Camus-,${ }^{4}$ los debates en la década de 1950 que versaron sobre el poder y el Estado, la autonomía y el autogobierno, la revolución y la rebelión. Camus ([1951] 1981a) expone de manera contundente la distinción entre revolución y rebelión, luego de apuntar que tras la Revolución Francesa razón o justicia se convirtieron en los principios formales y en la justificación del "dominio que no es ni justo ni razonable". Advirtió que la idea de revolución "va a separarse explícitamente del amor y la amistad, considera a los otros como un capital que se puede gastar... el hombre puede ser instrumento" (Camus, [1951] 1981a: 677), de modo que "de nuevo

\footnotetext{
${ }^{3}$ De Fanon destacan las obras Los condenados de la tierra ([1961] 2001) y Piel negra, máscaras blancas ([1952] 2009).

${ }^{4}$ Importante miembro de la rebelión anticolonialista argelina contra Francia, quien entre otras obras escribió "El hombre re belde" ([1951] 1981a) y "Moral y política" ([1950] 1981b).
} 
el mundo aparece bajo las especies de amo y de esclavo" (Camus, [1951] 1981a: 710). También defendió la rebelión como una exigencia estética. Fanon (2001 y 2009) plantea la necesidad de tomar en cuenta la subjetividad psíquica de los sujetos y el problema del racismo que priva por igual en todas las razas, clases y sujetos. Con él se inauguran los estudios que podrían denominarse "etnopsicoanáliticos", en los que se articulan de manera transdisciplinaria la antropología, el psicoanálisis y la filosofía política.

El debate se retoma de forma extraordinaria en Francia y México, entre otros espacios de lucha. En el caso de Francia, en 1968, destaca la participación de los colectivos 22 de Marzo, Socialismo o Barbarie, la Internacional Situacionista y la Federación Ibérica de Juventudes Libertarias, entre otros que generaron productos editoriales relevantes, como los de Cornelius Castoriadis (1983), Guy Debord (2002), Raoul Vaneigem (1988) y Tomás Ibáñez (2006). En consonancia, está la "revolución sin nombre" que reivindica la necesidad de "referirse explícitamente a la vida cotidiana, [para] comprender lo que hay de subversivo en el amor y de positivo en el rechazo de las obligaciones" (Vaneigem, 1988: 19), como única forma de preparar:

la revolución sin nombre, la revolución de la vida cotidiana... La revolución se realiza todos los días en contra de los revolucionarios especializados, una revolución sin nombre, como todo lo que brota de lo vivido, preparando, en la clandestinidad cotidiana de los gestos y los sueños, su coherencia explosiva (Vaneigem, 1988: 113-117).

Particularmente el pensamiento de Cornelius Castoriadis (1992), siempre anónimo, tuvo una influencia importante en las ideas que inspiraron el movimiento del 68 francés. Castoriadis publicaba con pseudónimos y realizaba su práctica política desde el colectivo Socialismo o Barbarie. Apuntala la exigencia de ir más allá de la racionalidad capitalista con ideas como la autonomía, el imaginario social instituyente, el reconocimiento de la psique y lo históricosocial para el conocimiento de la subjetividad histórica como determinante en la construcción de la realidad social y su alteridad permanente. Raoul Vaneigem y Guy Debord fueron fundadores de la Internacional Situacionista. Ambos caracterizaron al sistema político como una sociedad del espectáculo, donde el consumo de mercancías y la negación de los sujetos se convierten en la forma capitalista por excelencia. A su vez, Tomás Ibáñez (2006) planteó la crítica radical como forma de pensamiento desde la perspectiva anarquista, que es más "como una forma de ser que un discurso teórico". En el movimiento y el pensamiento anarquistas mexicanos podemos encontrar dos experiencias que denotan una ruptura con los modos de hacer política y de pensar desde los movimientos sociales y los sujetos que los generan: La Social en 1865-1878 y el Partido Liberal Mexicano de 1906 a 1918, que inauguran las formas anticapitalistas y antiestatistas de hacer política que a finales del siglo Xxi se encuentran con el movimiento zapatista. Sobre este tema, conviene remitirse al libro de Hugo Marcelo Sandoval Vargas (2011), quien además colabora en la sección de "Testimonios" de este número de la revista Desacatos con un texto sobre el movimiento anarcopunk en Guadalajara. Llegaríamos a los años noventa del siglo xx con la rebelión de los pueblos indígenas de Chiapas que, en palabras de su vocero principal, el subcomandante insurgente Marcos, reivindica su posición fuera de la lucha por el poder del Estado:

\footnotetext{
Pensamos que es posible organizarse para ir transformando el mundo, no desde arriba, no tomando el poder y desde ahí tomando medidas. Pensamos que la clave es organizarse para ir desde abajo alcanzando logros, satisfaciendo demandas. Cómo lo haremos, no sé, pero estoy seguro de que podemos resolverlo (subcomandante insurgente Marcos, 2001).
}

Es menester advertir que todos en este debate parecen coincidir en la apuesta por las personas sencillas y comunes, en sus capacidades y limitaciones, en sus posibilidades de construir la resistencia y la rebeldía, respetuosas de la ética como elemento cosustancial a 
la política y comprometidas en la lucha desde la trinchera de la resistencia. Y todos, como el subcomandante Marcos, acuden a la literatura para dar cuenta de la política, y a ésta para hacer la literatura de la rebelión y emprender la crítica incluso a la idea de revolución, si ésta se convirtiera en parte del proceso de reproducción de las relaciones sociales de dominación, así que se critica a la revolución entendida como hacer política para tomar el poder y controlar el Estado.

Por todo lo anterior, es pertinente retomar la cuestión del pensamiento desde la perspectiva del sujeto que tiene como horizonte político estar al margen de la racionalidad capitalista y la centralidad del Estado. Los artículos que conforman este número de Desacatos presentan a sujetos que han creado sus espacios para hacer política, para la autorreflexibilidad, donde ensayan nuevas formas de hacer política. Los autores de la sección "Saberes y razones" profundizan en los procesos de los sujetos para generar proyectos de autonomía y en la resistencia anticapitalista que llevan a cabo desde su cotidianidad, explícitamente o no. Estos sujetos - que se reconocen como tales- suponen una ruptura con las formas de reproducción de las relaciones de dominación capitalistas. Esta ruptura epistémica y ética manifiesta la discontinuidad de sus luchas y de la resistencia en el tiempo histórico y cómo se desarrollan en el tiempo actual. Los autores, que participan en luchas y resisten la dominación capitalista, han producido trabajos que parten de la perspectiva de los sujetos que analizan. Podemos esperar que el tema propuesto haya sido trabajado de manera que registre la subjetividad emergente que ocurre hoy sin circunscribirse necesariamente a las teorías sociales y el conocimiento heredado. Los lectores podrán observar que los autores logran un pensamiento epistémico - muestran el proceso de pensar-se en su propio movimiento- mediante el uso crítico de las categorías que los propios sujetos están creando además de las teorías.

Los trabajos expresan y exponen cómo los pueblos, comunidades, colectivos e individuos sociales se piensan en su hacer, cómo se constituyen y cómo despliegan su acción y su pensamiento con nuevos imaginarios sociales de acuerdo con sus deseos y no sin obstáculos, contradicciones y ambigüedades, lo cual es propio de la dialéctica del movimiento que se desarrolla sin que nazca aún lo nuevo de manera acabada. En este número de Desacatos tenemos el propósito de reconocer al sujeto como productor de realidades y saberes. Este aspecto es fundamental en el pensamiento crítico que cuestiona la fragmentación disciplinar en las ciencias sociales. Enfatizamos:

la discusión sobre el lugar del sujeto como productor de realidad y como productor de saberes locales que están más allá del conocimiento teórico-académico en el que se les reduce a sujetos de observación a modo de fenómenos y esencias objetivadas (Alonso y Sandoval, 2008).

Así lo constatan los artículos reunidos en este número de Desacatos. Esta cuestión, más que teórica, es un problema que corresponde al pensamiento epistémico y tiene mucho que aportar desde la antropología, con la condición de que evite la fragmentación disciplinaria que ha impuesto el academicismo de todo signo. Estamos frente a sujetos sociales que se reconocen como tales. Saben que su acción en el presente es desde donde configuran su por-venir. Son sujetos que, a partir de la apropiación consciente de su acción política, han des-investido la política de la pretensión de poder sobre los demás. Será importante mostrar que existen y que se declaran contra y más allá del Estado y el capital. Se advierte la conciencia respecto de la necesidad de conciencia histórica, política y sobre los condicionantes de lo subjetivo inconsciente que heredamos, pero que deviene como inconsciente cultural en la historia. Los procesos de investigación antropológica - pero también histórica, sociológica y psicoanalíticadesde la perspectiva del sujeto exigen el reconocimiento a la capacidad de reflexividad ${ }^{5}$ y de producir

\footnotetext{
${ }^{5}$ Reflexividad: Cualidad de reflexivo. Acostumbrado a actuar con reflexión. Véase <www.rae.es $>$.
} 
conocimiento, no sólo de procedimientos metodológicos y responsabilidad ética. Se trata de reconocer que todos somos capaces de argumentar: interpretar, criticar y debatir (Alonso y Sandoval, 2008).

Además de reconocerse como productores de circunstancias sociales, de darse cuenta de la posición en que se colocan frente a otros sujetos y sus proyectos, la subjetividad emergente que hoy se despliega en la lucha de resistencia anticapitalista pasa por un proceso de conciencia sobre la necesidad de conciencia acerca de sus potencialidades, su proyecto de futuro y la experimentación de nuevas formas de hacer política: la capacidad de advertir que están creando otro mundo sin esperar ni moverse al ritmo del Estado y el capital. Ahí están los zapatistas de México, los Sin Tierra de Brasil, los piqueteros y asambleas barriales de Argentina, los pueblos indios de Bolivia, Ecuador y Chile, los millones de chinos que habitan al margen de la economía formal, los millones de habitantes del Sudeste Asiático que llevan cientos de años en las periferias de los Estados- nación (Scott, 2009), por mencionar algunos de los que han trascendido en los medios de comunicación y estudios publicados, y que han dejado constancia de ello por medio de su propia producción escrita, con su propia narrativa y su historia oral.

El desafío de hacer antropología, historia, filosofía desde la perspectiva del sujeto se convierte en un reto epistémico-metodológico, implica hacer una etnografía en la que el análisis no admite la ingenuidad de los datos puros, en la que es necesario afrontar y cuestionar las estructuras conceptuales utilizadas, la pertinencia de una formación y experiencia acorde con lo por-venir. Se trata de un conocimiento antropológico que no se reduce al saber académico ni científico, pues es sólo una forma de saber de entre las diversas formas de conocimiento que dependen del sujeto que conoce su historia y su vida cotidiana, es decir, de su forma de vida (Alonso y Sandoval, 2008). Todo lo cual es cosustancial a la acción de reflexividad que resulta del pensar crítico y problematizador como práctica social de creación, individual y colectiva, que supone ir más allá de lo que existe, por lo que sólo se comprende en la acción, sólo se comprende lo que se vive. De ahí que sólo podemos comprender el sentido de las prácticas sociales en y con ellas, o sea desde su interior (Zibechi, 2007).

Las nuevas antropologías latinoamericanas decolonizadas han reconocido la necesidad de que el sujeto de la investigación no sea objetivado, sino que descubra su espacio de producción de conocimientos. Para entender y practicar esto, los antropólogos hemos tenido que experimentar una profunda ruptura epistemológica y ética. Tischler ejemplifica en este sentido cuando advierte que anteriormente se había pensado la historia de lucha de clases a partir de categorías homogéneas, que eran categorías de poder-dominio. No obstante, recomienda atender lo que han destacado los zapatistas, que reconocen que luchan contra las condiciones objetivas que les dañan, como la explotación y la dominación del capital, y contra ellos mismos por superarse en cuanto sujetos atravesados por esa relación (Tischler, 2008).

Habrá que recalcar que los articulistas de este número de Desacatos, tanto por lo que han escrito como por su propia práctica política, se reconocen como sujetos. Con todo, estarán bajo la mirada crítica de quien se pregunta y cuestiona autocríticamente y ha reflexionado a partir de un cuestionamiento ético y epistémico sobre si es posible coadyuvar a la constitución y despliegue de sujetos sociales potenciales por medio de la construcción de un conocimiento pertinente desde y sobre la realidad social sin que al mismo tiempo, o incluso antes, esos académicos e intelectuales se hayan constituido en sujetos sociales capaces de abrir y viabilizar ciertas opciones de realidad a partir de asumir un compromiso ético-político que se corresponda con una visión utópica o de futuro (Gallegos, 2009).

Los lectores podrán encontrar una articulación compleja pero complementaria en los trabajos incluidos en el presente número de Desacatos. Está garantizada una problematización que contribuya a desordenar el orden dominante, en la perspectiva de una ruptura de la clausura que representa la repetición de la teoría heredada (Miranda, 2010). 
Los autores llevan muchos años en esto y están situados histórica y políticamente, por lo que al dar cuenta de otros sujetos que como ellos luchan para defender la posibilidad de una vida digna, su propia vida y la de otros, lo que están haciendo implícitamente es ir más allá del Estado y el capital. Pero muchos otros individuos y colectivos están haciendo lo mismo en todos los puntos del planeta al decidir hacer las cosas de una forma propia, diferente a la que impera en todos los espacios de la vida social, distinta a la lógica reproductiva impuesta por el capital que es garantizada por su Estado.

\section{Bibliografía}

Adorno, Theodor, 1992, Dialéctica negativa, Taurus, Madrid. Alonso, Jorge y Rafael Sandoval, 2008, "Sujeto social y antropología. Despliegue de subjetividad como realidad y conocimiento", en Pablo González Casanova (coord.), Los conceptos de nuestro tiempo, Instituto de Investigaciones Sociales-Universidad Nacional Autónoma de México, México.

Archinov, Piotr, 2008, Historia del movimiento makhnovista: 1918-1921, Libros de Anarres, Buenos Aires.

Avrich, Paul, s/f, Kronstadt 1921, Libros de Anarres, Buenos Aires.

Bakunin, Mijail, 2004, Estatismo y anarquía, Libros de Anarres, Buenos Aires.

Benjamin, Walter, [1955] 2001, Ensayos escogidos, Ediciones Coyoacán, México.

2008, Tesis sobre el concepto de historia, Abada Editores, Madrid.

Bloch, Ernst, 2004, El principio esperanza, Trotta, Madrid.

Camus, Albert, [1951] 1981a, "El hombre rebelde", en Ensayos, Aguilar, Madrid, pp. 555-838.

- [1950] 1981b, "Moral y política", en Ensayos, Aguilar, Madrid, pp. 238-261.

Castoriadis, Cornelius, 1992, "Psique, imaginación e históricosocial”, entrevista realizada por Jean Claude Polack y Sparta Castoriadis, en Zona Erógena, núm. 1, en línea: <es.scribd.com/doc/23479599/castoriadispsique-imaginacion-e-historico-social-entrevista $>$.

— 1983, La institución imaginaria de la sociedad, vol. 1, Tusquets, Barcelona.

1998a, El psicoanálisis, proyecto y elucidación, Nueva Visión, Buenos Aires. 1998b, El mundo fragmentado, Altamira, Montevideo.

2003, La institución imaginaria de la sociedad, vol. 2, Tusquets, Buenos Aires.

Clastres, Pierre, 2001, Investigaciones en antropología política, Gedisa, Barcelona.

_ 2010, La sociedad contra el Estado, Hueders, Santiago de Chile.

Debord, Guy, 2002, La sociedad del espectáculo, Pre-textos, Valencia.

Ejército Zapatista de Liberación Nacional, 1994, El despertador mexicano, núm. 1.

, 1996, Documentos y comunicados, vol. 2, Era, México.

Fanon, Frantz, [1961] 2001, Los condenados de la tierra, Fondo de Cultura Económica, México.

—, [1952] 2009, Piel negra, máscaras blancas, Akal, Madrid.

Gallegos, Mónica, 2009, "Utopía y valores: ángulos de análisis en la construcción de la subjetividad", en Utopía en marcha, Horacio Cerutti y Jussi Takkasvirta, Abya-yala, Universidad de Helsinki, Helsinki.

Gandler, Stefan, 2009, Fragmentos de Frankfurt, Siglo XXI, México.

Holloway, John, 2002, Cambiar el mundo sin tomar el poder. El significado de la revolución hoy, Herramienta, Benemérita Universidad Autónoma de Puebla, Buenos Aires. 2011, Agrietar el capitalismo. El hacer contra el trabajo, Herramienta, Buenos Aires.

Ibáñez, Tomás, 2006, ¿Por qué? Fragmentos dispersos para un anarquismo sin dogmas, Anthropos, Barcelona.

Kropotkin, Piotr, 2001, Palabras de un rebelde, Edhasa, Barcelona.

Makhno, Nestor, s/f a, La Revolución Rusa en Ucracia 1918-1921, en línea: <www.nestormakhno.info/spanish/memorias/index.htm $>$, consultado el 10 de enero de 2010 .

, s/f b, "Lenin y el leninismo, ¿guías del proletariado mundial?", en línea: <www.nestormakhno.info/ spanish/lenin.htm $>$, consultado el 10 de enero de 2010.

Miranda, Rafael, 2010, "La noción de alteridad en Cornelius Castoriadis", tesis de doctorado, Universidad Complutense de Madrid, Madrid.

Sandoval Álvarez, Rafael, 2006, Nuevas formas de hacer política. Una subjetividad emergente, Centro Universitario de Ciencias Sociales y Humanidades-Universidad de Guadalajara, Guadalajara.

2008, El zapatismo urbano de Guadalajara. Contradicciones y ambigüedades en el quehacer político, Instituto Nacional de Antropología e Historia, México. 
Sandoval Vargas, Hugo Marcelo, 2011, La configuración del pensamiento anarquista en México. El horizonte libertario de La Social y el Partido Liberal Mexicano, Universidad de Guadalajara, México.

Scott, James, 2009, The Art of Not Being Governed. An Anarchist History Upland Southeast Asia, Yale University Press, New Haven.

Subcomandante insurgente Marcos, 1999, La Cuarta Guerra Mundial, 20 de noviembre, en línea: <www.inmotionmagazine.com>.

__, 2001, "Entrevista con Matilde Campodómico y Eduardo Blasima”, en El Observador de Uruguay, 24 de marzo.

Tischler, Sergio, 2008, "Pensando el zapatismo, Entrevista con Sergio Tischler y Fernando Matamoros", en John
Holloway, Fernando Matamoros y Sergio Tischler, Zapatismo. Reflexión teórica y subjetividades emergentes, Herramienta, Instituto de Ciencias Sociales y Humanidades-Benemérita Universidad Autónoma de Puebla, México, pp. 107-142.

Vaneigem, Raoul, 1988, Tratado del saber vivir para uso de las jóvenes generaciones, Anagrama, Barcelona.

Volin [Vsévolod Mijaillovich Eichenbaum], 2007, La revolución desconocida, Hormiga Libertaria, Gato Negro, México.

Velasco Criado, Demetrio, 1993, Ética y poder político en Mijail Bakunin, Universidad de Deusto, Bilbao.

Zibechi, Raúl, 2007, Autonomías y autoemancipaciones. América Latina en movimiento, Universidad Nacional de San Marcos, Lima. 